The INL is a

U.S. Department of Energy

National Laboratory

operated by

Battelle Energy Alliance

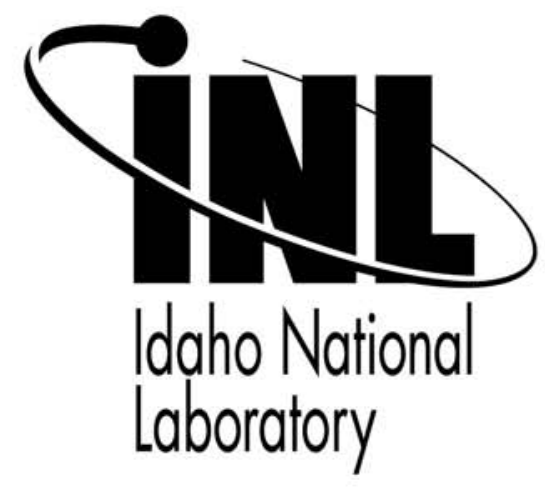

INL/CON-14-31248

PREPRINT

\section{EFFECTS OF THE FOIL FLATNESS ON THE STRESS-STRAIN CHARACTERISTICS OF U10MO ALLOY BASED MONOLITHIC MINI- PLATES}

\section{Proceedings of the ASME 2014 International Mechanical Engineering Congress \& Exposition}

\author{
Hakan Ozaltun, Pavel Medvedev
}

\section{November 2014}

This is a preprint of a paper intended for publication in a journal or proceedings. Since changes may be made before publication, this preprint should not be cited or reproduced without permission of the author. This document was prepared as an account of work sponsored by an agency of the United States Government. Neither the United States Government nor any agency thereof, or any of their employees, makes any warranty, expressed or implied, or assumes any legal liability or responsibility for any third party's use, or the results of such use, of any information, apparatus, product or process disclosed in this report, or represents that its use by such third party would not infringe privately owned rights. The views expressed in this paper are not necessarily those of the United States Government or the sponsoring agency. 


\section{IMECE2014 - 36605}

\section{EFFECTS OF THE FOIL FLATNESS ON THE STRESS-STRAIN CHARACTERISTICS OF U10MO ALLOY BASED MONOLITHIC MINI-PLATES}

\author{
Hakan Ozaltun \\ Idaho National Laboratory \\ Idaho Falls/ID - USA
}

\author{
Pavel Medvedev \\ Idaho National Laboratory \\ Idaho Falls/ID - USA
}

\begin{abstract}
The effects of the foil flatness on stress-strain behavior of monolithic fuel mini-plates during fabrication and irradiation were studied. Monolithic plate-type fuels are a new fuel form being developed for research and test reactors to achieve higher uranium densities. This concept facilitates the use of low-enriched uranium fuel in the reactor. These fuel elements are comprised of a high density, low enrichment, U-Mo alloy based fuel foil encapsulated in a cladding material made of Aluminum.
\end{abstract}

To evaluate the effects of the foil flatness on the stress-strain behavior of the plates during fabrication, irradiation and shutdown stages, a representative plate from RERTR-12 experiments (Plate L1P756) was considered. Both fabrication and irradiation processes of the plate were simulated by using actual irradiation parameters. The simulations were repeated for various foil curvatures to observe the effects of the foil flatness on the peak stress and strain magnitudes of the fuel elements.

Results of fabrication simulations revealed that the flatness of the foil does not have a considerable impact on the post fabrication stress-strain fields. Furthermore, the irradiation simulations indicated that any post-fabrication stresses in the foil would be relieved relatively fast in the reactor. While, the perfectly flat foil provided the slightly better mechanical performance, overall difference between the flat-foil case and curved-foil case was not significant. Even though the peak stresses are less affected, the foil curvature has several implications on the strain magnitudes in the cladding. It was observed that with an increasing foil curvature, there is a slight increase in the cladding strains.

Keywords: U10Mo, Monolithic Fuel Plate, Irradiation, Foil Flatness, Finite Element Analysis

$\triangle$ Corresponding Author: Email address: Hakan.Ozaltun@inl.gov Tel: (208) 5260274 | Fax: (208) 5262930

\section{INTRODUCTION}

Part of Global Threat Reduction Initiative (GTRI) program, High Performance Research Reactors Fuel Development $\left(\right.$ HPRR-FD ${ }^{(1)}$ ) program has operated with the primary objective of developing the essential technologies to minimize the use of highly enriched uranium (HEU) in civilian applications. The principle vehicle by which this goal is sought is through the conversion of research and test reactors to the use of low-enriched uranium fuels (LEU, $<20 \%{ }^{235} \mathrm{U}$ ) [1]. However, lower uranium enrichment requires higher fuel densities either as dispersion fuels at high volume loading, or in a monolithic form to compensate lower fission rates.

For the conversion of high performance research reactors to low enrichment Uranium fuel, U-Mo alloy based fuels in monolithic form were proposed. These plate-type fuels consist of a high uranium density, LEU foil contained within a diffusion barrier, and encapsulated within a cladding. Materials for these fuel elements are U-10Mo for the fuel foil, Zirconium for the diffusion barrier and Al6061-O for the cladding. For the foil material, various alloys were evaluated and it was found that U-Mo alloys are the most promising candidate for this purpose. Molybdenum extends the stability of the cubic gamma phase and this phase is known to be stable under typical irradiation conditions. Additionally, U-Mo alloy has a low neutron capture cross-section, good irradiation behavior, and an acceptable swelling response [2-4].

Early RERTR experiments indicated that the presence of an interaction layer between the fuel and the cladding materials causing mechanical problems. To minimize the potential fuelcladding interaction, several design modifications were proposed. One of them is an inclusion of a diffusion barrier between the fuel and the cladding materials. The plates with diffusion barriers with $0.025 \mathrm{~mm}$ thick Zirconium produced a satisfactory irradiation performance.

(1) Formerly RERTR, Reduced Enrichment for Research and Test Reactors 
Several steps involve in the fabrication process of a monolithic plate. The initial stage of the fabrication process is the preparation of coupons made of U10Mo alloy. For this, Uranium and Molybdenum feedstock is melted in an inert atmosphere and casted into thin sheets. Then, the sheets are machined or rolled to produce thin coupons. In order to control inter-diffusion phenomenon which occurs at the fuelcladding interface during the irradiation process, U10Mo coupons are laminated with Zirconium diffusion barrier prior the hot rolling process.

To apply Zirconium liners on each faces of the coupons, corolling technique is used. For this, U10Mo coupon is placed between two thin Zirconium layers (Zr-U10Mo-Zr). Then, layers are positioned in a frame made of low carbon steel. Cover plates are placed to the top and bottom of the layers; and finally, the assembly is welded before the rolling process. The sheets are hot rolled at approximately $650{ }^{\circ} \mathrm{C}$. Multiple hot rolling passes is performed to minimize occurrence of micro cracks. Typical number of hot passes is $20-40$ for the preparation of a $0.25-0.50 \mathrm{~mm}$ thick Zr-U10Mo co-rolled foil. Once reduction via hot co-rolling is completed, the coupon assembly is placed into a furnace for 45 minutes at $650{ }^{\circ} \mathrm{C}$ to reduce the residual stresses and minimize the material anisotropy. Finally, heat treated Zr-U10Mo co-rolled foils are removed from the rolling assembly by trimming the perimeters of coupons.

The final stage of the foil preparation is to reduce the thickness of Zr-U10Mo co-rolled foil to its targeted value via cold rolling process. Typical thickness reduction is 0.015 $0.025 \mathrm{~mm}$ per pass. Final thickness of the co-rolled foil varies depending on the reactor application. The cold rolling process creates smoother foil surfaces and lead to more uniform foil thickness facilitating higher quality of the bonds during subsequent Hot Pressing process [5-7].

Finally, the co-rolled foils are encapsulated in a cladding material via Hot Isostatic Pressing (HIP), completing the fabrication process. For this, a co-rolled foil (trimmed to target dimensions prior HIP) is placed between two layers of Aluminum cladding material (A16061-O for RERTR fuel plates). These layers are subjected to a HIP procedure conducted at a temperature of $560{ }^{\circ} \mathrm{C}$ and a pressure of 104 $\mathrm{MPa}$ for 90 minutes before being cooled to room temperature at a rate of $4.8{ }^{\circ} \mathrm{C} / \mathrm{min}$ with diminishing the pressure as described in details elsewhere [8]. Once the HIP process is completed, the fuel plates have a total thickness of $1.397 \mathrm{~mm}$. These plates are then trimmed to $101.473 \mathrm{~mm} \times 25.400 \mathrm{~mm}$. Inside the cladding, the foil and liners have a nominal thickness of $0.254 \mathrm{~mm}$ and $0.0254 \mathrm{~mm}$, respectively. Nominal dimensions of the final product are shown in Fig. la.

Mini-plates are then assembled into capsules made of AL6061-T6. There are 4 capsules named A, B, C and D from top to bottom, and each capsule can hold 8 mini-plates. Containing 32 mini-plates, the capsule assembly is then positioned vertically in a basket. The plates are cooled by a direct contact with the primary coolant.

There are concerns that if the flatness of the foil has implications on stress-strain behavior of the plates and on overall irradiation performance, as it is not always the case to fabricate the plates with perfectly flat fuels in the center. The aim of this work is to investigate and characterize these effects. Over the course of this study, the fully coupled thermo-mechanical behavior of a selected plate was simulated. Between the simulations, curvature of the foil was varied from perfectly flat case to the limiting case. A comparative evaluation was made to determine the sensitivity of the plate's performance to the flatness of the fuel foil.

In this study, the plate L1P756 from RERTR-12 test matrix was considered. This plate was irradiated at frontal neutron flux configuration (face-on orientation) in position D-5 (the bottom row of Capsule D). The plate was in $1^{\text {st }}$ slot in the capsule, between the coolant channels 1 and 2 . This setup was shown schematically in Fig. 1 b.

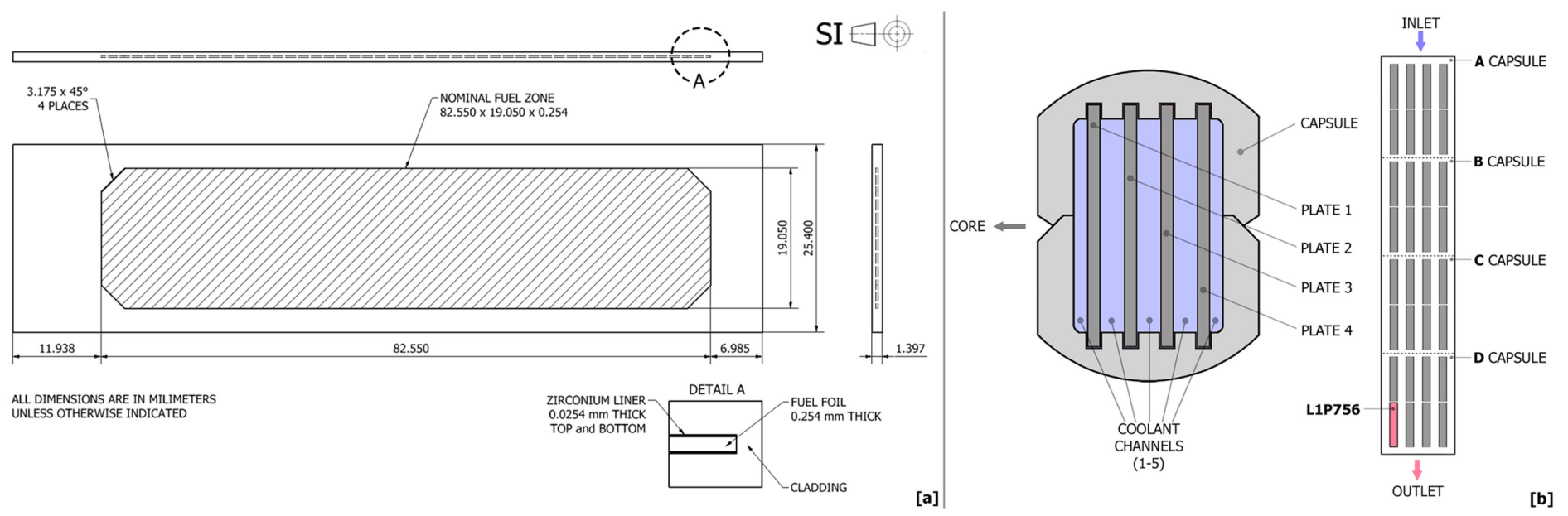

Figure 1 (a) Mini-plate dimensions that were used in the model (b) Capsule, coolant channels and position of L1P756 


\section{IRRADIATION PARAMETERS}

The plate L1P756 was irradiated in 2 cycles of RERTR-12. Total irradiation time for the plate was 89.7 days. Effective irradiation times with respect to cycles are 50.5 days in cycle 146A; and, 39.2 days in cycle 146B.

The experimental data for the fission power density, fast neutron flux, fast neutron fluence and average fission density for these 2 cycles are summarized in Table 1. These variables were implemented via utility subroutines accordingly. In the models, a linear interpolation was used to estimate the values between the known data points. In Fig.2, resulting models and their comparison with experimental data are shown.

Due to a frontal flux orientation, local to average ratio (L2AR) of the fission density varies with respect to spatial coordinates. Fig. 3 shows the fission density L2AR in axial direction (Fig.3a), in transverse direction (Fig.3b), and actual 2D mapping with respect to spatial coordinates (Fig.3c).

It is important to note that an accurate implementation of the fission density is crucial for the fidelity of the results, as many irradiation parameters are affected by the local fission density;

Table 1 Irradiation Parameters for the plate L1P756 [9]

\begin{tabular}{|c|c|c|c|c|c|c|}
\hline \multirow{2}{*}{$\begin{array}{l}\text { Irradiation } \\
\text { Cycle }\end{array}$} & \multicolumn{2}{|c|}{$\begin{array}{l}\text { Irradiation } \\
\text { Time }\end{array}$} & $\begin{array}{l}\text { Fission Power } \\
\text { Density }\end{array}$ & $\begin{array}{c}\text { Fast Neutron } \\
\text { Flux }\end{array}$ & $\begin{array}{l}\text { Fast Neutron } \\
\text { Fluence }\end{array}$ & $\begin{array}{c}\text { Average Fission } \\
\text { Density }\end{array}$ \\
\hline & [days] & [hours] & {$\left[\mathrm{W} / \mathrm{cm}^{3}\right]$} & {$\left[\mathrm{n} / \mathrm{m}^{2}-\mathrm{sec}\right]$} & {$\left[\mathrm{n} / \mathrm{m}^{2}\right]$} & {$\left[\right.$ fission $\left./ \mathrm{m}^{3}\right]$} \\
\hline \multirow{4}{*}{$\begin{array}{c}146 \mathrm{~A} \\
50.5 \mathrm{EFPD}\end{array}$} & 0 & 0 & 31410.95 & $2.06 \mathrm{E}+18$ & $0.00 \mathrm{E}+00$ & $0.00 \mathrm{E}+00$ \\
\hline & 16 & 384 & 29244.27 & $2.08 \mathrm{E}+18$ & $2.85 E+24$ & $1.45 \mathrm{E}+27$ \\
\hline & 32 & 768 & 28252.78 & $2.03 E+18$ & $5.73 E+24$ & $2.80 \mathrm{E}+27$ \\
\hline & 50.5 & 1212 & 27111.33 & $1.99 \mathrm{E}+18$ & $8.98 \mathrm{E}+24$ & $4.31 \mathrm{E}+27$ \\
\hline \multirow{4}{*}{$\begin{array}{c}146 \mathrm{~B} \\
39.2 \mathrm{EFPD}\end{array}$} & 50.5 & 1212 & 24908.87 & $1.71 \mathrm{E}+18$ & $8.98 \mathrm{E}+24$ & $4.31 \mathrm{E}+27$ \\
\hline & 68.5 & 1644 & 23412.37 & $1.79 \mathrm{E}+18$ & $1.16 \mathrm{E}+25$ & $5.60 \mathrm{E}+27$ \\
\hline & 78.5 & 1884 & 22923.41 & $1.77 \mathrm{E}+18$ & $1.32 \mathrm{E}+25$ & $6.28 \mathrm{E}+27$ \\
\hline & 89.7 & 2152.8 & 22334.53 & $1.75 \mathrm{E}+18$ & $1.49 \mathrm{E}+25$ & $7.03 E+27$ \\
\hline
\end{tabular}
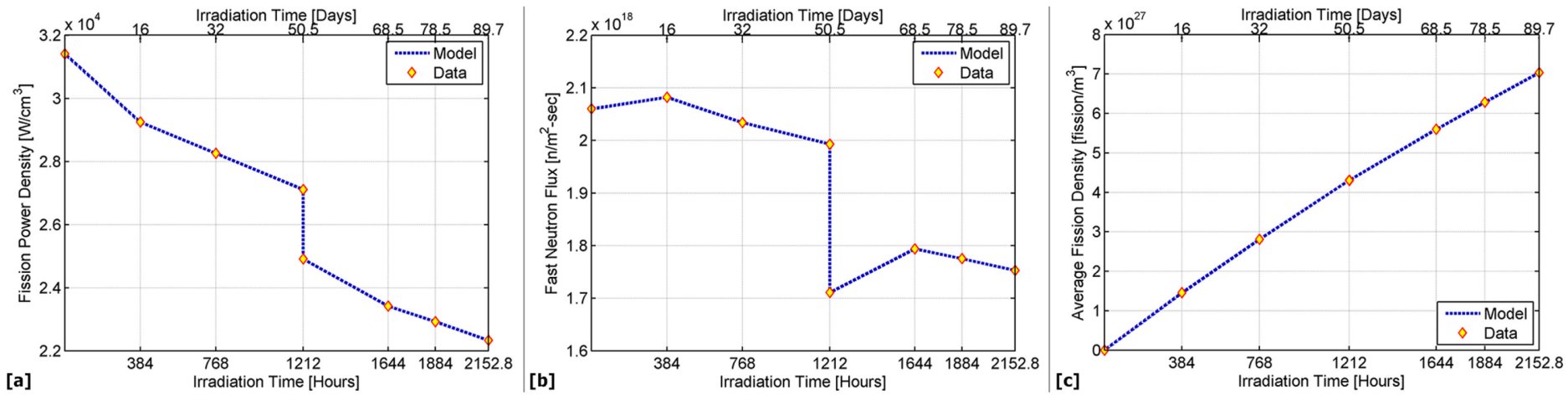

Figure 2 Irradiation Parameters (a) Fission Power Density (b) Fast Neutron Flux (c) Average Fission Density
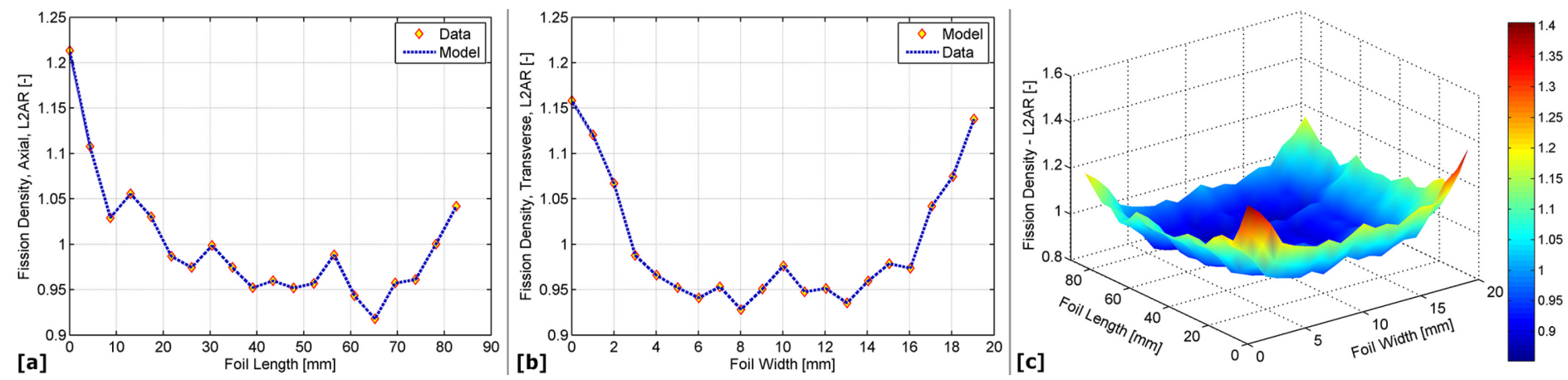

Figure 3 Fission Density, L2AR (a) Axial direction (b) Transverse direction (c) 2D field over the foil 
such as, volumetric heat generation, foil swelling, irradiation creep, conductivity degradation etc.

The average fission density in the fuel foil was constructed as a linear interpolation of ordered pairs of average fission density and time shown in Fig.2c. This function is called on each material point to return the value of the average fission density. The value for the local to average fission density ratio along the lengthwise and widthwise edges of the foil was implemented at twenty points, which are spaced equally from each other along those respective spatial dimensions. Linear interpolations were used to calculate L2AR between the grid points in the length and width directions. The resulting interpolation values were multiplied (bi-linear interpolation) to yield a surface mapping field of the L2AR fission density across the fuel foil as shown in Fig.3c. Finally, the local fission density at a given time was calculated as the product of the average fission density and the local to average fission density ratio at each material point within the fuel foil.

Volumetric heat generation rate due to fissions is shown in Fig. $2 a$. Data for the average power density was gathered from the neutronics calculations and it was implemented as a function of the irradiation time. Between the time points, a linear interpolation was used to approximate the fission power density at a specific irradiation time. The average fission power density (Fig.2a) was then multiplied by the Local to Average Ratio of the fission density (Fig. 3c) to calculate the local volumetric heat generation at a specific location and time. This procedure was repeated for the each material point.

Shown in Fig.2b, the data for the fast neutron flux was gathered from the neutronics calculations. Similar with the heat generation rate, it was also implemented as a function of irradiation time. A linear interpolation was used to calculate the flux and fluence at a specific time for each material point. Values for the fast neutron fluence were used to simulate the irradiation effects on Al6061 cladding and Zirconium liner. These irradiation effects that were considered in this work are irradiation hardening, swelling and creep.

\section{FINITE ELEMENT MODEL}

The geometric model was created by using the nominal dimensions that were shown in Fig.1. A full model was utilized to account the different temperature profiles for different channels and the coolant temperature increase in the channels.

C3D8RT element of ABAQUS, an 8-node thermally coupled brick, tri-linear displacement and temperature with reduced integration and hourglass control, was used. Chamfered edges were represented by $7 \times 7 \times 10$ nodal divisions. Equally spaced 4 layers were used to represent the thickness of the foil. Nodal divisions along the length and width directions are 174 and 42, respectively. A total number element on the foil was 29168 bricks. Equally spaced 3 layers were used to represent the thickness of the Zirconium liner. Similar with the foil, each of the Zirconium liners utilized 174 and 42 divisions along its length and width direction, respectively. This resulted 21876 hexahedral for one liner, and total 43752 hexahedral for the both liners. The thickness of the cladding material was represented by 16 layers. The nodal divisions along the length and the width directions of the cladding are 214 and 56, respectively. The total number element on the cladding was 121448.

For all four parts of the plate, a mapped meshing with sweeping technique was used to match the elements and the nodal points at the interfaces. The total number of elements in the plate was 194368 hexahedral. Resulted finite element discretization of the geometry is shown in Fig. 4.

It was assumed that the bonding between the foil, cladding and $\mathrm{Zr}$ liner are ideal and there are no defects present prior irradiation. It was also assumed that no interfacial delamination occurs during the irradiation process. Therefore, all nodal points at the interfaces were tied together. The plate was modeled as free to move in all directions, except along its long edges. At the longitudinal edges, only the sliding motion was permitted, as these edges are constrained by the rails of the capsule. One single node on cladding corner was fixed to prevent rigid body motion.

For this work, two consecutive simulations were performed, namely, fabrication and irradiation. Irradiation simulation used the stress-strain results from the fabrication simulation as an initial state for the irradiation. Residual stress and strain fields caused by the cooling stage of the HIP process were calculated via a fully coupled, temperature-displacement simulation.

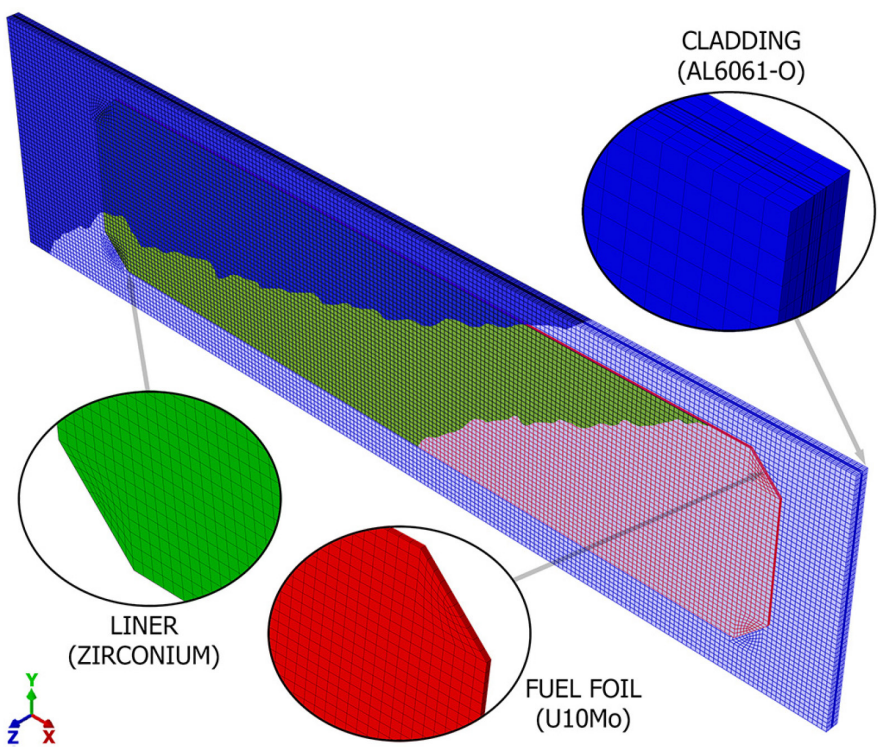

Figure 4 3D Model and FE discretization 
Fabrication simulation was built by using a transient step of 6737 seconds with a predefined initial and a final temperature fields. The predefined temperature field was $560{ }^{\circ} \mathrm{C}$ (HIP temperature) and was uniform throughout the plate. The subsequent step introduced a room temperature as a boundary condition across the surface of the plate, and the temperature was then allowed to decrease during the transient. Cooling rate was $4.8{ }^{\circ} \mathrm{C} / \mathrm{min}$. Symmetry condition was applied to the corresponding nodes at the mid-plane of the plate. A single node at the volumetric center was fixed to prevent rigid body motion. The results of this simulation were then passed to the irradiation simulation to define the initial state.

Irradiation process was modeled for 2152.8 hours (89.7 days). Time history was divided into 2 sub-steps for each irradiation cycles (cycle 146A and cycle 146B). Irradiation cycle 146A was simulated for 1212 hours (50.5 days) followed by $146 \mathrm{~B}$ for 940.8 hours (39.2 days).

To implement the field variables, ABAQUS utility subroutines were created accordingly. The USDFLD user routine was used to define the local fission density within the fuel foil with respect to the spatial coordinates and the irradiation time. This subroutine was also used to calculate the fast neutron flux and fluence for the cladding and the liner materials. Thermal conductivity degradation of the fuel foil was implemented as a function of the local fission density. It was introduced to the model via an independent field variable.

The irradiation induced creep and the models for the gaseous, solid and total swelling for the fuel foil was implemented in the user subroutine CREEP. Irradiation effects in the cladding material such as swelling strain and neutron hardening was included in this routine also.

The fission power density of the fuel foil was introduced as a body heat flux in the model. Local volumetric heat generation of the foil was calculated by using L2AR of the fission density. Heat transfer calculations between the plate surface and the primary coolant were performed by using Petukhov correlation. A film condition was created on the cladding surface and experimental coolant channel temperatures were used for the channel definition.

Plate edges along the lengthwise and widthwise directions were constrained (sliding only) to simulate the mechanical restrictions resulted by the fuel capsule restraints. A single node at the outer corner of the plate was fixed to prevent rigid body motion.

A fully coupled thermal-displacement transient solver with active swelling-creep-viscoelastic behavior was used. An explicit-implicit integration scheme was selected for the solver. Maximum time increment per step was set to be 12 hours and maximum temperature increment per step was set to be $5{ }^{\circ} \mathrm{C}$ to avoid numerical instabilities.

\section{MATERIAL MODELS}

Material models that were used in this study are: U10Mo for the fuel, Zirconium for the liner, AL6061-O for the cladding, and light water at $2.52 \mathrm{MPa}$ for the coolant models. Material properties that were used for the model are in Appendix A.

Model for the thermal conductivity degradation of the fuel material was adapted from Hayes [10] and expressed by,

$k_{p}=k_{0} \times e^{(-2.14 \times P)}$

where $k_{0}$ is the thermal conductivity of the fully dense material, $P$ is the porosity factor (valid for $P \leq 0.3$ ) and $k_{p}$ is the thermal conductivity of the porous medium.

Porosity factor, $P$ was calculated via,

$$
P=\frac{\left(\Delta V / V_{0}\right)_{g}}{\left(\Delta V / V_{0}\right)_{g}+1}
$$

where $\left(\Delta \mathrm{V} / \mathrm{V}_{0}\right)_{\mathrm{g}}$ is swelling due to the gaseous products. The model for the gaseous swelling was adapted from [11] as,

$$
\begin{array}{lr}
\left(\frac{\Delta V}{V_{0}}\right)_{g}=1.0 \cdot f_{d} & \begin{array}{r}
f_{d} \leq 3 \times 10^{27} \\
\text { fis } / \mathrm{m}^{3}
\end{array} \\
\left(\frac{\Delta V}{V_{0}}\right)_{g}=3.0+2.3 \cdot\left(f_{d}-3\right)+0.33 \cdot\left(f_{d}-3\right)^{2} & f_{d}>\begin{array}{r}
3 \times 10^{27} \\
\text { fis } / \mathrm{m}^{3}
\end{array}
\end{array}
$$

where $\left(\Delta \mathrm{V} / \mathrm{V}_{0}\right)_{\mathrm{g}}$ gaseous swelling in $(\%)$ and $f_{d}$ is local fission density in $\times 10^{27}$ (fissions $/ \mathrm{m}^{3}$ ).

Irradiation induced creep model is based on Kim [12] as,

$\dot{\varepsilon}=A \cdot \sigma \cdot \dot{f}$

where, $\dot{\varepsilon}$ is creep strain rate $(1 / \mathrm{sec}), A$ is irradiation creep coefficient $\left(500 \times 10^{-25} \mathrm{~cm}^{3} / \mathrm{MPa}\right.$-fis $), \sigma$ is equivalent stress $(\mathrm{MPa})$ and $\dot{f}$ is fission density rate (fissions $/ \mathrm{cm}^{3}-\mathrm{sec}$ ).

The model for the fuel meat swelling due to fission products is based on the relation given by $\mathrm{Kim}[11]$ as,

$$
\begin{array}{lr}
\left(\frac{\Delta V}{V_{0}}\right)_{f}=5.0 \cdot f_{d} & \begin{array}{r}
f_{d} \leq 3 \times 10^{27} \\
\text { fis } / \mathrm{m}^{3}
\end{array} \\
\left(\frac{\Delta V}{V_{0}}\right)_{f}=15+6.3 \cdot\left(f_{d}-3\right)+0.33 \cdot\left(f_{d}-3\right)^{2} & f_{d}>\begin{array}{r}
3 \times 10^{27} \\
\text { fis } / \mathrm{m}^{3}
\end{array}
\end{array}
$$

where $\left(\Delta \mathrm{V} / \mathrm{V}_{0}\right)_{\mathrm{f}}$ total volumetric swelling of the fuel in $(\%)$, and $f_{d}$ is the local fission density in $\times 10^{27}$ (fissions $/ \mathrm{m}^{3}$ ). 


\section{COOLANT CHANNEL MODEL}

Models for thermo-physical properties of the water were develop via the data reported by NIST [13]. Mathematical relations were developed for the coolant at $2.52 \mathrm{MPa}$, the nominal operating pressure of ATR. Valid temperature range for the models is $1-100{ }^{\circ} \mathrm{C}$. In the models, $T$ is in ${ }^{\circ} \mathrm{C}$.

Density $\left(\mathrm{kg} / \mathrm{m}^{3}\right)$ was defined according to

$\rho=1.46 \times 10^{-5} \cdot T^{3}-5.664 \times 10^{-3} \cdot T^{2}+3.318 \times 10^{-3} \cdot T+1001$

The model for the specific heat $(\mathrm{J} / \mathrm{kg}-\mathrm{K})$ is

$C_{p}=2.462 \times 10^{-6} \cdot T^{4}-6.120 \times 10^{-4} \cdot T^{3}+6.169 \times 10^{-2} \cdot T^{2}-$

$$
2.459 \cdot T+4206
$$

Thermal diffusivity model $\left(\mathrm{m}^{2} / \mathrm{sec}\right)$ is

$\alpha=-2.068 \times 10^{-12} \cdot T^{2}+5.562 \times 10^{-10} \cdot T+1.334 \times 10^{-7}$

The model for thermal conductivity $(\mathrm{W} / \mathrm{m}-\mathrm{K})$ is

$k=-9.565 \times 10^{-6} \cdot T^{2}+2.147 \times 10^{-3} \cdot T+0.5609$

Kinematic viscosity $\left(\mathrm{m}^{2} / \mathrm{sec}\right)$ is

$$
\begin{aligned}
v= & 3.009 \times 10^{-14} \cdot T^{4}-8.433 \times 10^{-12} \cdot T^{3}+9.291 \times 10^{-10} \cdot T^{2}- \\
& 5.321 \times 10^{-8} \cdot T+1.758 \times 10^{-6}
\end{aligned}
$$

Dynamic viscosity (Pa-s) is

$$
\begin{aligned}
\mu= & 2.986 \times 10^{-11} \cdot T^{4}-8.382 \times 10^{-9} \cdot T^{3}+9.259 \times 10^{-7} \cdot T^{2}- \\
& 5.332 \times 10^{-5} \cdot T+0.00176
\end{aligned}
$$

The model for Prandtl Number is

$$
\begin{aligned}
\operatorname{Pr}= & 2.632 \times 10^{-7} \cdot T^{4}-7.336 \times 10^{-5} \cdot T^{3}+7.970 \times 10^{-3} \cdot T^{2}- \\
& 0.4396 \cdot T+13.13
\end{aligned}
$$

Reynolds Number was calculated according to

$$
\operatorname{Re}=\frac{\rho \cdot v \cdot D_{H}}{\mu}
$$

Where, $v$ is velocity and $D_{H}$ is hydraulic diameter. Coolant velocities are, $12.61 \mathrm{~m} / \mathrm{sec}$ and $10.18 \mathrm{~m} / \mathrm{sec}$ for inner and outer channels, respectively. Hydraulic diameter $\left(D_{H}\right)$ is

$$
D_{H}=4 A / P
$$

where $A$ is the cross sectional area and $P$ is the wetted perimeter of the cross-section.
For L1P756 plate in position D5, the channel widths are $1.4986 \mathrm{~mm}$ for the outer channel (Channel 1). The inner channel (Channel 2) is $2.3876 \mathrm{~mm}$ wide (1.1938 was used due to a channel symmetry). The channel length is $22.555 \mathrm{~mm}$ for the both channels.

Nusselt number was calculated by using Petukhov-Gnielinski correlation [14]. For a fully developed turbulent and transition flow $(\operatorname{Re}>2300)$, the Nusselt number is given by

$$
N u=\frac{\left(\frac{f}{8}\right) \cdot(\operatorname{Re}-1000) \cdot \operatorname{Pr}}{1+12.7 \cdot\left(\frac{f}{8}\right)^{1 / 2} \cdot\left(\operatorname{Pr}^{2 / 3}-1\right)}
$$

Where, $\operatorname{Pr}$ is the Prandtl number $(0.5 \leq \operatorname{Pr} \leq 2000)$, Re is the Reynolds number $\left(3000<\operatorname{Re}<5 \times 10^{6}\right)$ and $f$ is the friction factor from the first Petukhov equation.

Friction factor in Eqn.17 was calculated according to

$$
f=\left(\frac{1}{0.790 \cdot \ln (R e)-1.64}\right)^{2}
$$

The heat transfer coefficient was calculated by

$h=\frac{k}{D_{H}} \cdot N u$

where, $h$ is heat transfer coefficient $\left(\mathrm{W} / \mathrm{m}^{2}-\mathrm{K}\right), k$ is thermal conductivity $(\mathrm{W} / \mathrm{m}-\mathrm{K}), D_{H}$ is hydraulic diameter $(\mathrm{m}), N u$ is the Nusselt Number.

The heat transfer between the coolant and the plate surface was simulated by creating a surface interaction, which defines a film condition at the plate surfaces. Surface film condition was created by using coolant temperatures reported in [9] and calculated heat transfer coefficients (Eqn.17) shown in Fig.5.

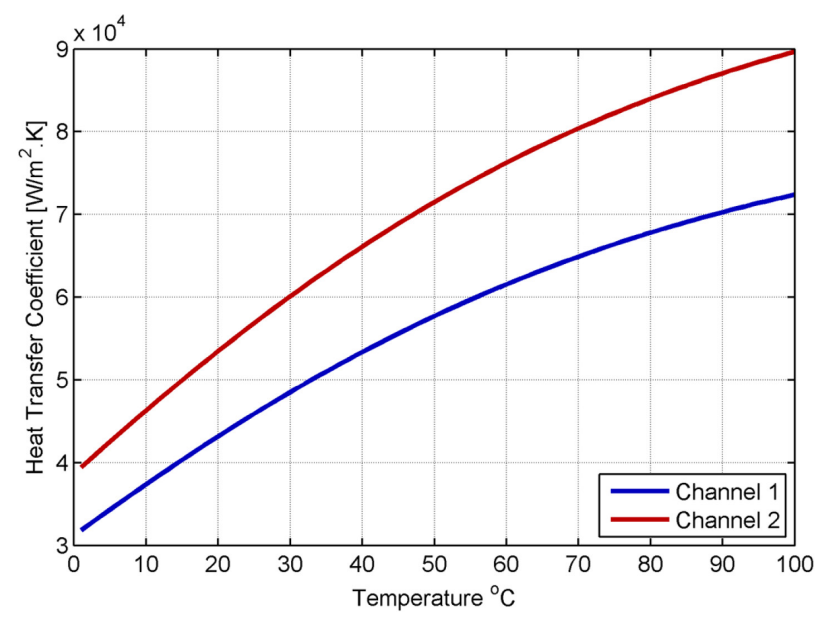

Figure 5 Heat transfer coefficient for the channels 


\section{RESULTS AND DISCUSSIONS}

\subsection{Fabrication (HIP)}

The fabrication model simulated the cooling stage of the HIP process from $560{ }^{\circ} \mathrm{C}$ to $21^{\circ} \mathrm{C}$. Cooling time to reach a steady state is 6737 seconds. The cooling rate is $4.8{ }^{\circ} \mathrm{C} / \mathrm{min}$. Fig. 6 shows the stress-strain fields at the end of the cooling stage.

Shown in Fig. 6a, the equivalent stress contour indicates that the foil stresses would be ranging from $140 \mathrm{MPa}$ to $296 \mathrm{MPa}$. Peak stresses are located at the foil ends. Lowest stresses are located on the perimeter of the foil.
The stress field in the Zr-liner is shown in Fig.6b. Even though stresses in the liner have similar patterns with those in the foil, the magnitudes in the liner are higher. Stresses are ranging from 329 to $344 \mathrm{MPa}$.

Fig. $6 c$ shows the equivalent stresses in the cladding. The peak stresses $(70.13 \mathrm{MPa})$ are found to be at the interface region with $\mathrm{Zr}$-liner and at the contact area with the perimeter of the foil. Equivalent strain field in cladding is in Fig. $6 \mathrm{~d}$. The peak strains are computed to be $0.601 \%$. In figure, the detailed view from the $x-y$ plane (mid-plane) reveals that the peak cladding strains are at the perimeter of the contact region with the fuel foil.

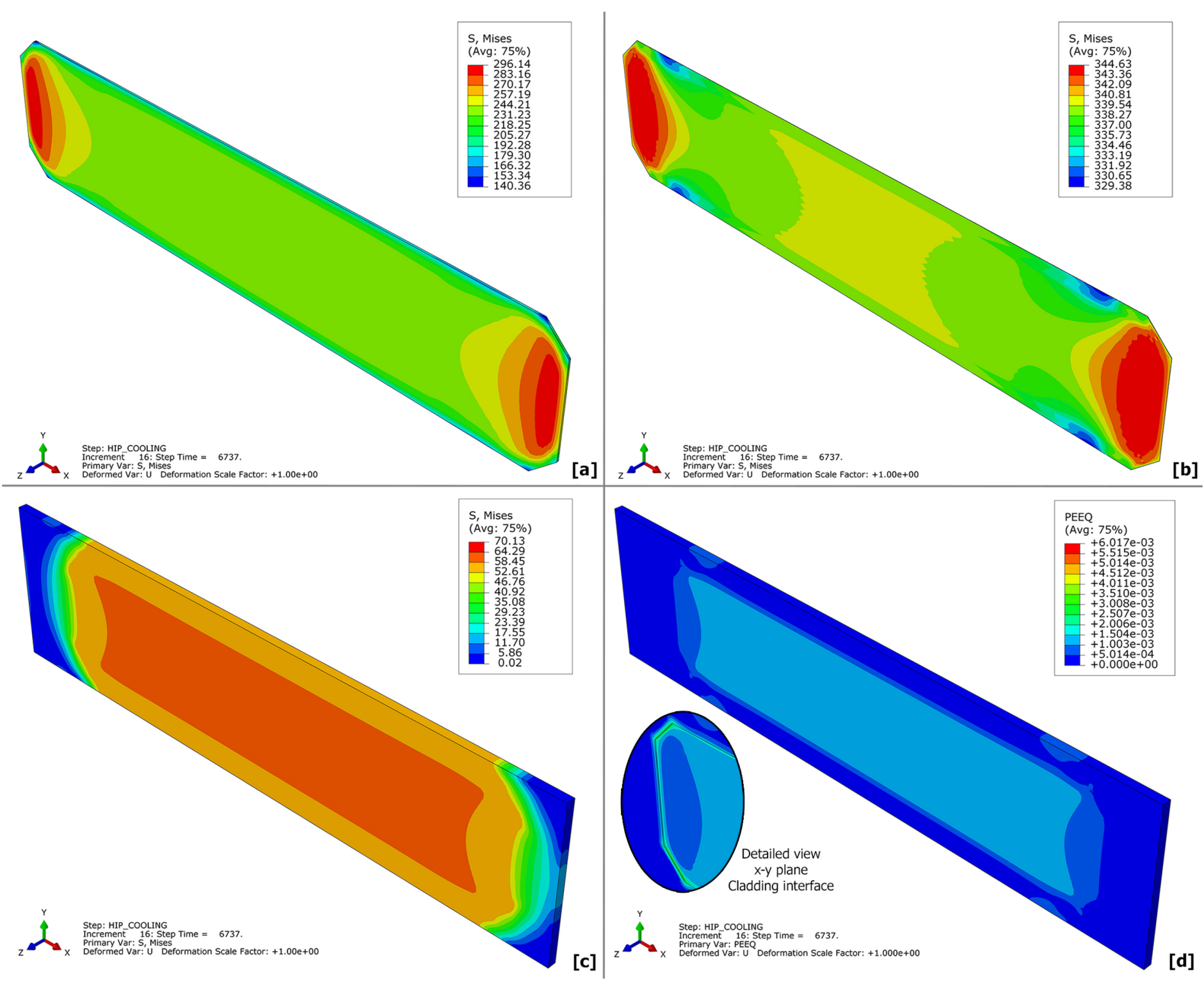

Figure 6 End of fabrication process, Contours are showing

(a) Equivalent stress [MPa] in the fuel foil (b) Equivalent stress [MPa] in $\mathrm{Zr}$ liner

(c) Equivalent stress $[\mathrm{MPa}]$ in the cladding (d) Equivalent plastic strains $[\mathrm{mm} / \mathrm{mm}]$ in the cladding 


\subsection{Irradiation}

To evaluate the plate performance, irradiation of the plate L1P756 was simulated for 2152.8 hours ( 89.7 days) via 2 substeps, namely, cycle 146A for 50.5 EFPD and cycle 146B for 39.2 EFPD. The temperature fields for the end of the cycle 146B (end of irradiation) are shown in Fig.7.

In the figure, the temperature fields of the foil at the interface with the Zirconium liner (Fig.7a); and, at the foil centerline (Fig.7b) are shown. Results are for the end of the irradiation, at which, the plates are at $22334.53\left[\mathrm{~W} / \mathrm{cm}^{3}\right]$ power, just before the reactor shutdown.

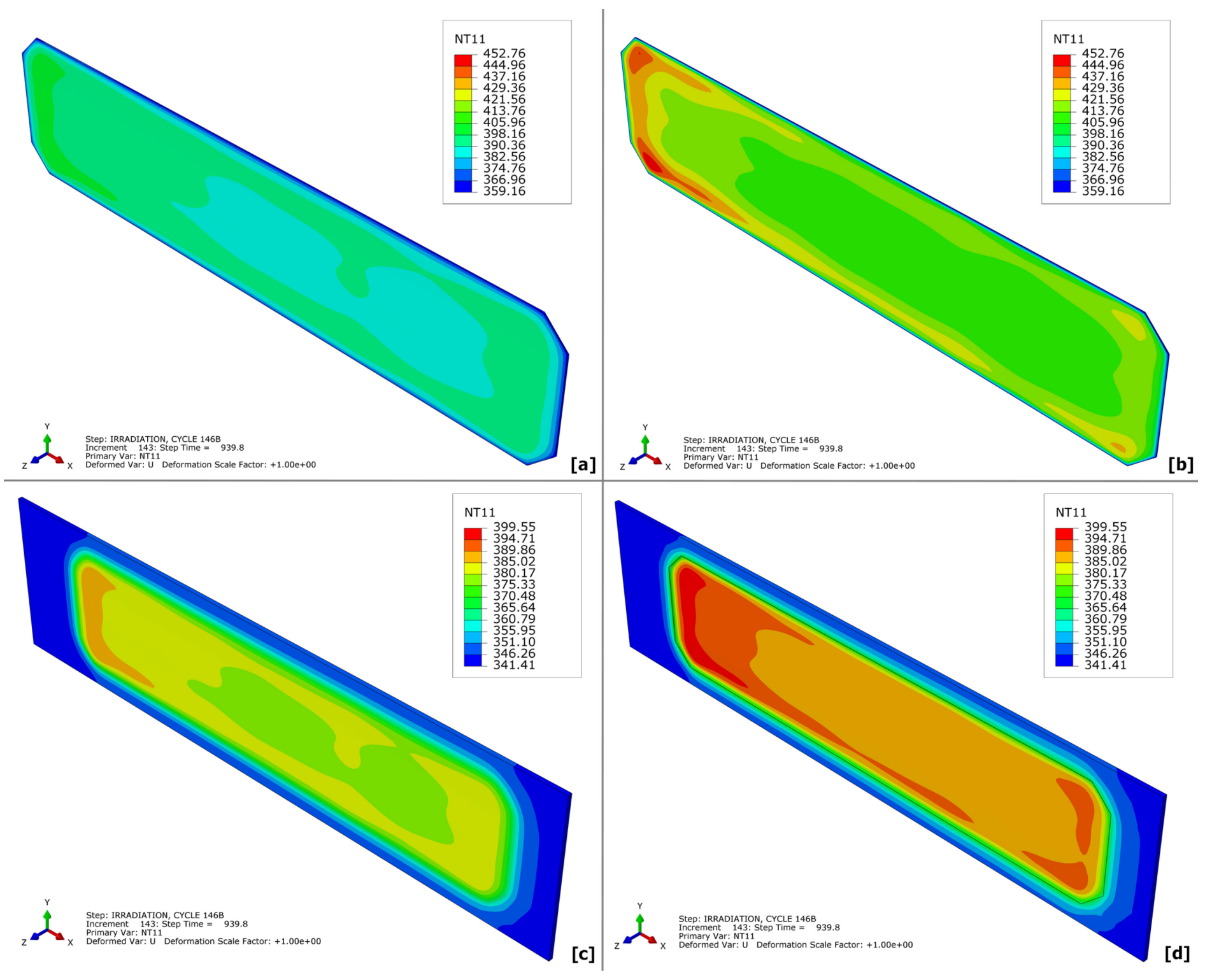

The peak foil temperatures were found to be in the inlet side, where the fission densities are the highest. Calculated peak foil temperatures are $130.98{ }^{\circ} \mathrm{C}\left(404.13{ }^{\circ} \mathrm{K}\right)$ at the interface (Fig. 7a) and $179.61^{\circ} \mathrm{C}\left(452.76^{\circ} \mathrm{K}\right)$ at the centerline (Fig. $\left.7 b\right)$. Minimum foil temperature was calculated to be $86.01{ }^{\circ} \mathrm{C}$ $\left(359.16^{\circ} \mathrm{K}\right)$ around the foil perimeter.

The temperature fields for the cladding at the interface and at the plate surface are shown in Fig.7c and Fig. $7 d$ From the figures, the peak temperatures for the cladding are $126.40{ }^{\circ} \mathrm{C}$ $\left(399.55^{\circ} \mathrm{K}\right)$ at the interface, and $109.23{ }^{\circ} \mathrm{C}\left(382.38^{\circ} \mathrm{K}\right)$ at the surface. The lowest cladding temperature is $68.26{ }^{\circ} \mathrm{C}(341.41$ $\left.{ }^{\circ} \mathrm{K}\right)$. The peaks are closer to the inlet side. 
The fission density on the foil reaches to $9.15 \times 10^{27}\left[\mathrm{fis} / \mathrm{m}^{3}\right]$ with L2AR of 1.302 at the inlet side as seen in Fig. 8 a. The calculated swelling strain due to gaseous products on the foil is in Fig. $8 b$. From the figure, the minimum gaseous swelling on the foil is $13.02 \%$. Reaching to its peak closer to the inlet side, the maximum gaseous swelling is $29.64 \%$.

The large gaseous swelling has implications on the integrity of the foil. It is shown that the gaseous swelling has a critical breakaway value and can be used to predict a failure [15]. It was formulated that when the gaseous swelling approaches $33.3 \%$, the bubbles touch neighboring bubbles in a randomly arranged configuration, assisting interconnection of the pores, and thus, facilitating escape of the gaseous products to the surface. It is also reported that an upper limit of $30 \%$ for gaseous swelling is often observed [15-17]. By using this information, it may be claimed that if the gaseous swelling increases beyond $30 \%$ foil may become critical and any gaseous swelling above $33.3 \%$ may lead to a breakaway failure. A closer examination of swelling results in Fig. $8 \mathrm{~b}$ indicates that no regions in the fuel foil reach to a critical breakaway value that would cause a breakaway failure.

In Fig. $8 c$, contour mapping for the irradiation induced creep in the fuel is shown. The minimum creep strain is $21.9 \%$ at the mid-section of the foil. The larger creep strain is observed around the entire perimeter of the foil. The peak irradiation creep strain is $79.1 \%$ and it is located at the inlet side.

Shown in Fig. $8 d$, the displacement contours in the thickness direction reveals a bulging. The maximum displacement in the thickness direction was computed to be $0.240 \mathrm{~mm}(0.120 \mathrm{~mm}$

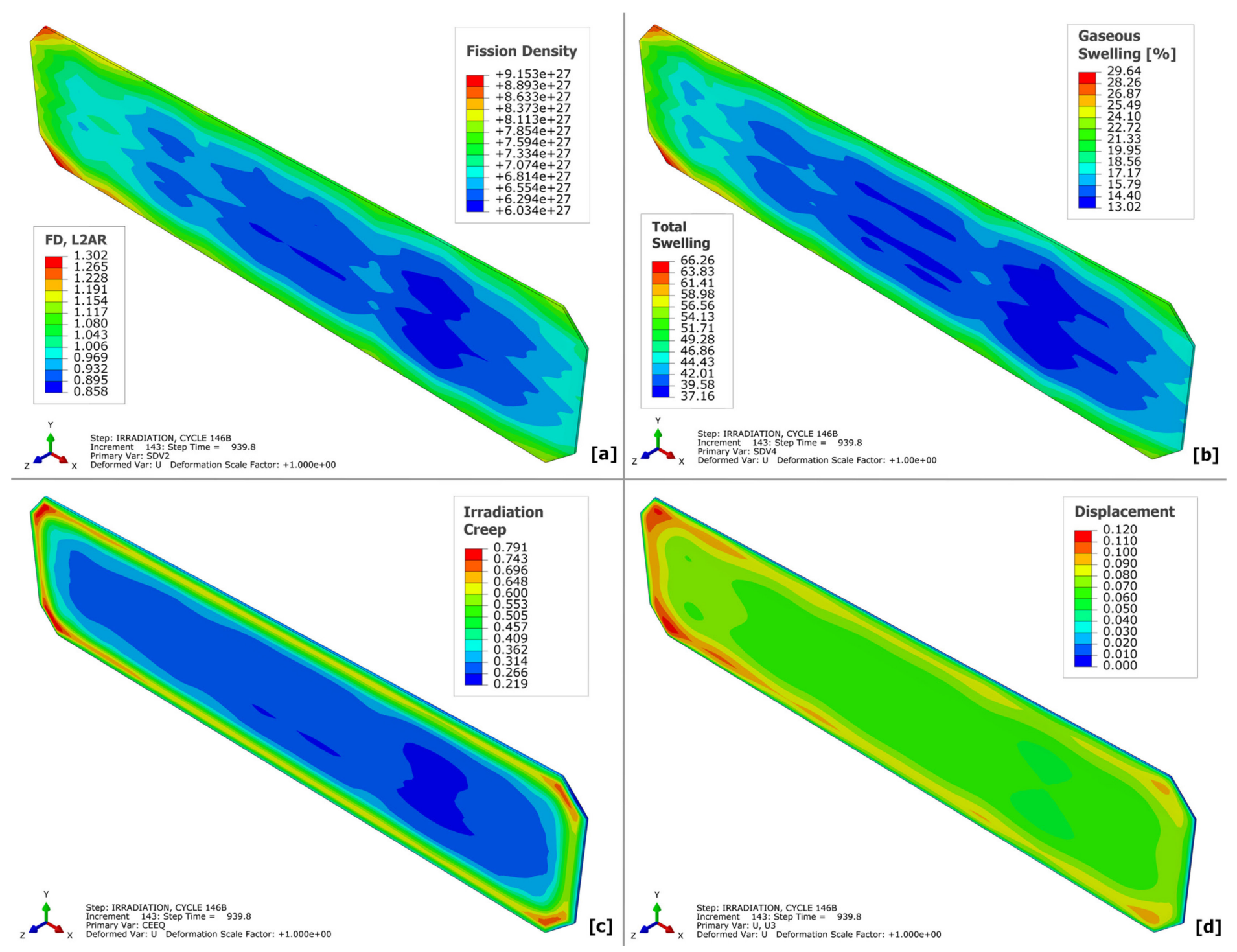

Figure 8 Contour plots for the foil at the end of the irradiation process

(a) Local fission density [fis $/ \mathrm{m}^{3}$ ] and L2AR (b) Gaseous swelling [\%] and regions with 33.3\% and more gaseous swelling (c) Irradiation induced creep strain in the foil (d) Total displacement [mm] of the foil in the thickness direction 
with respect to the mid-plane) at the inlet side. This corresponds to approximately $95 \%$ swelling. Other regions of high displacements are observed at the perimeter of the foil.

Equivalent stress fields for the foil, cladding and liner materials are shown in Fig.9. The stress fields at the end of the irradiation (end of the cycle 146B, plate at $22334.52 \mathrm{~W} / \mathrm{cm}^{3}$ power) can be seen in Fig.9a. The results indicate that the stresses on the foil are negligible. However, the residual stresses would develop during the shutdown as shown in Fig.9b. From the figure, an equivalent stress of $70 \mathrm{MPa}$ is present on the regions closer to the inlet side.

Prior irradiation, residual stresses due to the fabrication process on the foil were ranging from $140 \mathrm{MPa}$ to $296 \mathrm{MPa}$ as discussed in Sec.6.1. Irradiation simulations have revealed that fabrication induced stresses in the foil are relieved in less than 12 hours due to a high irradiation creep strain. This implies that the fuel foil would be essentially stress-free in the reactor.

During irradiation, a slight decrease in the fabrication stresses in the $\mathrm{Zr}$-liner is observed. Peak equivalent stress is approximately $300 \mathrm{MPa}$ around the perimeter as shown in Fig.9c. This reduction is due to the relaxation of the foil by irradiation creep and thermal creep in Zr-liner material. Unlike the foil material, stresses in the cladding increase during irradiation. For the cladding material, the residual stress due to fabrication was computed to be $71.35 \mathrm{MPa}$. Fig.9d reveals that the stresses increase to $150 \mathrm{MPa}$. This is due to irradiation hardening. Additional stresses in the cladding are also produced by the strains as a result of the volumetric swelling of the foil.

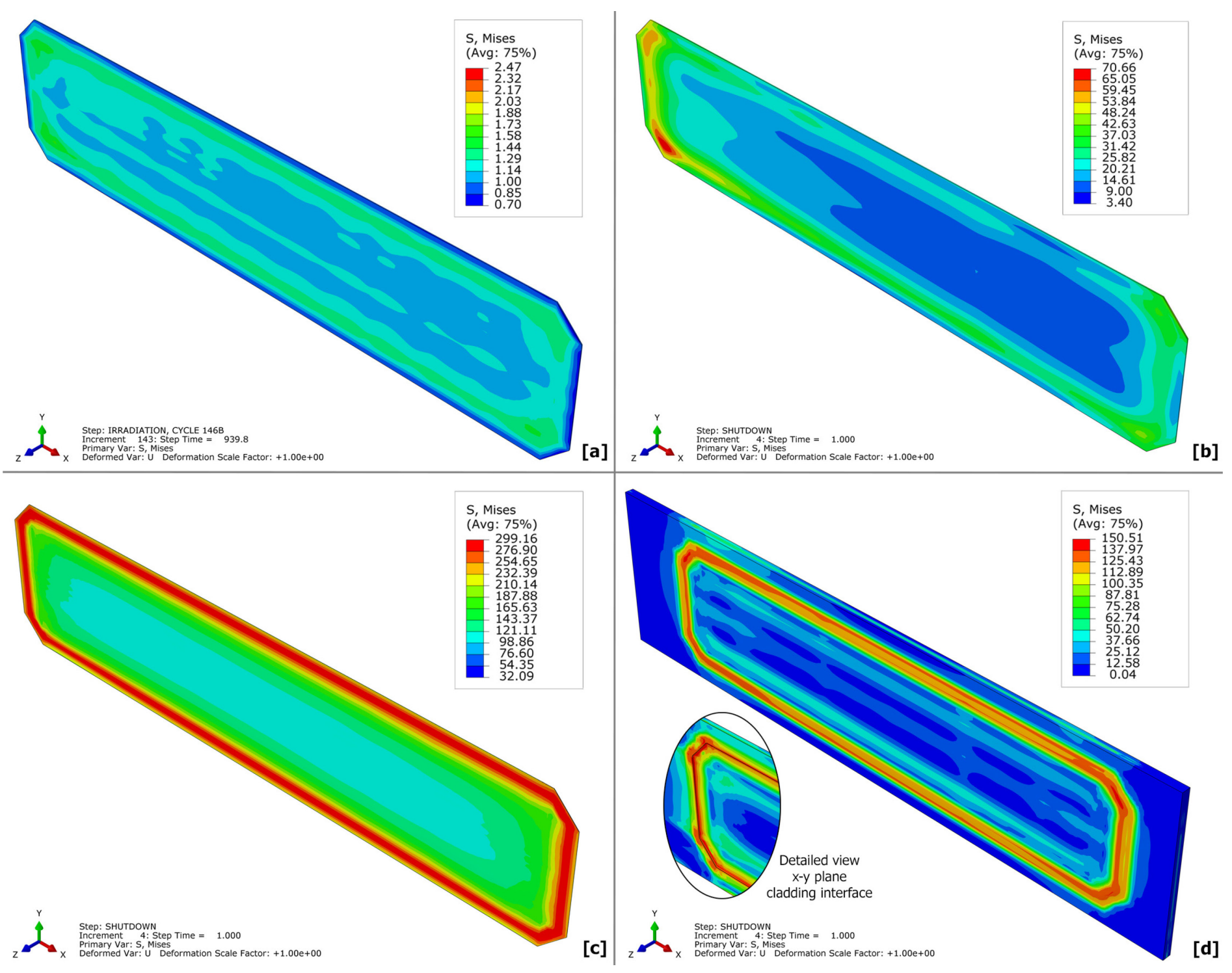

Figure 9 Equivalent stress [MPa] fields for the foil and the cladding, contours are showing (a) Foil, end of irradiation, (89.7 days, at $22334.53\left[\mathrm{~W} / \mathrm{cm}^{3}\right]$ ) (b) Foil, centerline view, end of shutdown

(c) Zr-liner, showing interface with the fuel, end of shutdown (d) Cladding, end of shutdown 


\subsection{Case Studies: Effects of Foil Flatness}

The results for the fabrication and irradiation processes of the plate L1P756 with a centered flat foil were previously discussed. There are concerns that if the flatness of the foil has implications on stress-strain behavior of the plates and on overall irradiation performance. The aim of this section is to investigate and characterize these effects. For this, a sensitivity study was performed. Between the simulations, curvature of the foil was varied from the perfectly flat case to the limiting case as shown schematically in Figure 10. The limiting case is the minimum allowable cladding thickness, which is 0.152 $\mathrm{mm}$.

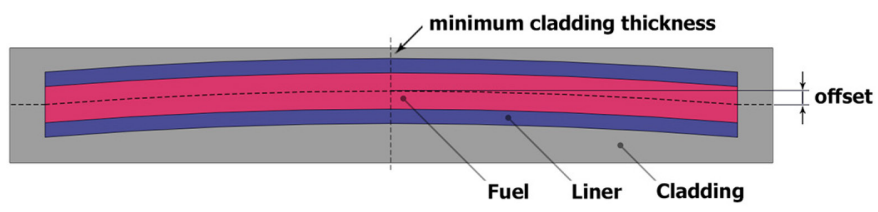

Figure 10 Foil curvature study

The new models utilized the same irradiation parameters with the previous plate (L1P756). All geometric specifics that were presented in Fig. 1 were kept unchanged, except the flatness of the foil. For the fabrication and irradiation models, total 6 distinct curvatures were evaluated as tabulated in Table 2.

Table 2 Evaluated cases for the plate L1P756

\begin{tabular}{ccccc}
\hline Cases & \multicolumn{2}{c}{$\begin{array}{c}\text { Foil curvature } \\
\text { Centerline offset }\end{array}$} & $\begin{array}{c}\text { Cladding } \\
\text { thickness }\end{array}$ & Details \\
\hline & {$[\%]$} & {$[\mathrm{mm}]$} & {$[\mathrm{mm}]$} & {$[-]$} \\
\hline 1 & 0 & 0.000 & 0.5461 & Nominal Thickness \\
2 & 25 & 0.063 & 0.4826 & - \\
3 & 50 & 0.127 & 0.4191 & - \\
4 & 75 & 0.190 & 0.3556 & - \\
5 & 100 & 0.254 & 0.2921 & - \\
6 & 155 & 0.393 & 0.1524 & Minimum Cladding \\
\hline
\end{tabular}

Fig.11 shows the evolution of the peak stress-strains during fabrication and irradiation with respect to the foil curvature. The fabrication constrain for this study is the minimum allowable cladding thickness, which is defined as $0.152 \mathrm{~mm}$. In the figures, the centerline offset $0.000 \mathrm{~mm}$ represent the nominal case (perfectly flat foil), and centerline offset of 0.393 $\mathrm{mm}$ is the upper bound, which corresponds to the minimum cladding thickness of $0.152 \mathrm{~mm}$. Results in the figure indicated that the peak foil and cladding stresses for fabrication and irradiation parts are not affected significantly by the flatness of the foil.

The magnitudes of the peak strains are shown in Fig.11c. From the figure, the peak cladding strains are affected considerably by the flatness of the foil. As expected, the lowest strain magnitudes can be achieved by the flat foil (foil centerline offset $=0.000 \mathrm{~mm}$ ). If a flatness of the foil is not preserved, the peak cladding strains increase roughly $50 \%$. Once it is deviated, further changes of the foil curvature do not change the peak strains further.

\section{CONCLUSIONS}

Irradiation performance of the plate L1P756 from RERTR-12 was evaluated. The effects of the flatness of the foil on the plate's stress-strain characteristics during the fabrication, irradiation and reactor shutdown were studied.

It is found that the flatness of the foil does not impact the peak stresses as the magnitudes are comparable for various curvature distances. The stresses are slightly lower at the midsection for the case with a flat foil. For the strain fields, evaluation of the profiles and magnitudes for various cases indicated that shape of the foil has several implications on the strain characteristics of the cladding material.

Flat foil case has provided the lowest peak strains; and thus, more desirable from mechanical perspective. On the other hand, requesting a perfectly flat foil in a plate especially after HIP might not be easy or feasible. Changes in the peak strains of the cladding material are less significant with an increasing curvature, once the flatness is strayed. While the peak strains are located at the perimeter of the bond region with the foil, the strain magnitudes in other region of the cladding are significantly lower.

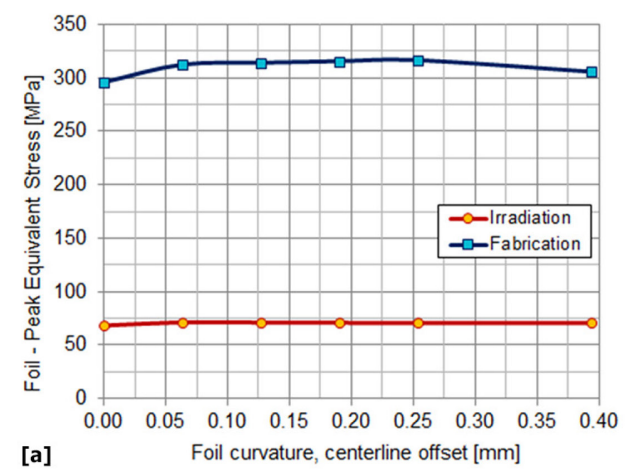

Figure 11 (a) Equivalent stresses in the fue
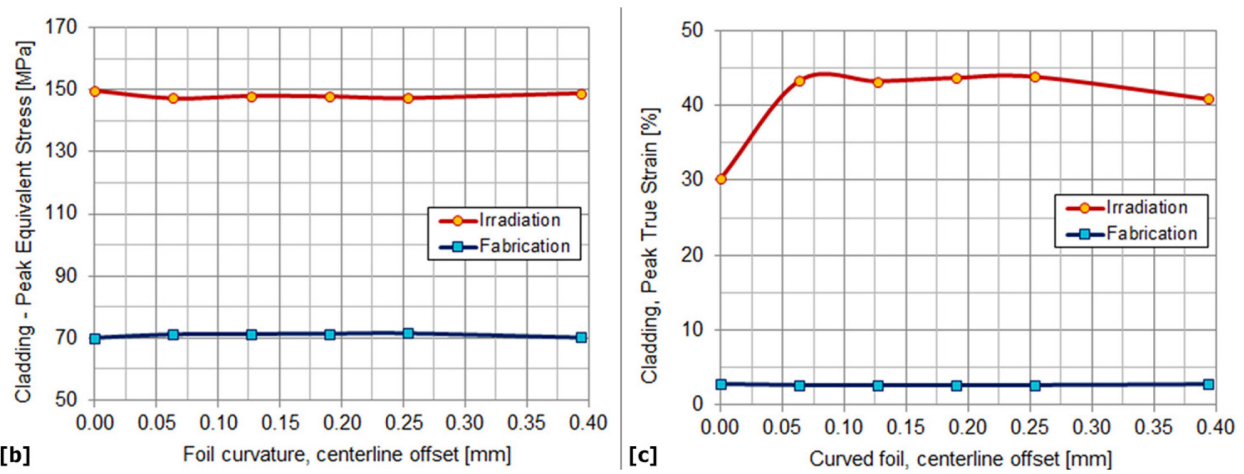

(b) Equivalent stresses in the cladding (c) Total strains in the cladding 


\section{NOMENCLATURE}

$A \quad$ Power law multiplier for irradiation creep

$A_{c} \quad$ Cross sectional area of the coolant channel

$C_{p} \quad$ Specific Heat

$D_{H} \quad$ Hydraulic diameter

$f \quad$ Friction factor from the first Petukhov equation

$f_{d} \quad$ Fission density

$\dot{f} \quad$ Fission density rate

$h \quad$ Heat transfer coefficient

$k \quad$ Thermal conductivity

$\mathrm{Nu} \quad$ Nusselt number

$P \quad$ Porosity

$P_{c} \quad$ Wetted perimeter of the cross-section

$\mathrm{Pr} \quad$ Prandtl number

Re Reynolds number

$V \quad$ Volume

$\alpha \quad$ Thermal diffusivity

$\dot{\varepsilon} \quad$ Equivalent creep strain rate

$\mu \quad$ Dynamic viscosity

$\rho \quad$ Density

$\tilde{\sigma} \quad$ Equivalent deviatoric stress

$\sigma_{e q} \quad$ Equivalent stress

$v \quad$ Kinematic viscosity

\section{ACKNOWLEDGMENTS}

This work was supported in part by an allocation of computing time from High Performance Computing facilities of Idaho National Laboratory.

\section{US DOE DISCLAIMER}

This manuscript has been authored under Contract DE-AC0705ID14517 with the US Department of Energy. The US Government retains and the publisher, by accepting the article for publication, acknowledges that the US Government retains a nonexclusive, paid-up, irrevocable, world-wide license to publish or reproduce the published form of this manuscript, or allow others to do so, for US Government purposes.

This information was prepared as an account of work sponsored by an agency of the U.S. Government. Neither the U.S. Government nor any agency thereof, nor any of their employees, makes any warranty, express or implied, or assumes any legal liability or responsibility for the accuracy, completeness, or usefulness of any information, apparatus, product, or process disclosed, or represents that its use would not infringe privately owned rights. References herein to any specific commercial product, process, or service by trade name, trademark, manufacturer, or otherwise, does not necessarily constitute or imply its endorsement, recommendation, or favoring by the U.S. Government or any agency thereof. The views and opinions of authors expressed herein do not necessarily state or reflect those of the U.S. Government or any agency thereof.

\section{REFERENCES}

[1] J. L. Snelgrove, G. L. Hofman and M. K. Meyer, "Development of very high density low-enriched Uranium fuels," J. Nucl. Eng. Des., vol. 178, p. 119-12, 1997.

[2] D. B. Lee, K. H. Kim and C. K. Kim, "Thermal compatibility studies of un-irradiated U-Mo alloys dispersed in Aluminum," J. Nucl. Mater., vol. 250, pp. 79-82, 1997.

[3] M. K. Meyer, G. L. Hofman, S. L. Hayes and C. R. Clark, "Low temperature irradiation behavior of U-Mo alloy dispersion fuels," J. Nucl. Mater., vol. 304, pp. 221236, 2002.

[4] J. M. Park, K. H. Kim, C. K. Kim, M. K. Meyer, G. L. Hofman and R. V. Strain, "The irradiation behavior of atomized U-Mo alloy fuels at high temperature," J. Met. Mater. Int., vol. 7, no. 2, p. 151-157, 2001.

[5] G. A. Moore and M. C. Marshall, "Co-Rolled U10Mo/Zirconium-Barrier-Layer Monolithic Fuel Foil Fabrication Process," INL/EXT 10-17774 Idaho National Laboratory Technical Report, Idaho Falls, 2010.

[6] G. A. Moore, F. J. Rice, N. E. Woolstenhulme, J. Jue and B. H. Park, "Monolithic Fuel Fabrication Process Development at the Idaho National Laboratory," in RERTR 2009 - 31st International Meeting on Reduced Enrichment for Research and Test Reactors, Beijing, China, 2009.

[7] G. A. Moore, "Fabrication Control Plan for the RERTR12 Experiment," PLN-3254 - Idaho National Laboratory Technical Report., Idaho Falls, 2010.

[8] J. F. Jue, H. P. Blair, R. C. Curtis, A. M. Glenn and D. K. Dennis, "Fabrication of monolithic RERTR fuels by Hot Isostatic Pressing," J. Nucl. Technol, vol. 172, no. 2, pp. 204-210, 2010.

[9] D. M. Perez, G. S. Chang, D. M. Wachs and G. A. Roth, "RERTR-12 Irradiation Summary Report, INL/EXT-1227085," INL, Idaho Falls/ID, 2012.

[10] S. L. Hayes, G. L. Hofman, M. K. Meyer and J. Rest, "Modeling of high density of U-Mo dispersion fuel plate performance," in 24th International Meeting on Reduced Enrichment for Research and Test Reactors (RERTR), San Carlos de Bariloche, Argentina, 2002.

[11] Y. S. Kim and G. L. Hofman, "Fission product induced swelling of U-Mo alloy fuel," Journal of Nuclear Materials, vol. 419, pp. 291-301, 2011.

[12] Y. S. Kim, G. L. Hofman, J. S. Cheon, A. B. Robinson and D. M. Wachs, "Fission induced swelling and creep of U-Mo alloy fuel," Journal of Nuclear Materials, vol. 437, pp. 37-46, 2013.

[13] E. W. Lemmon, M. L. Huber and M. O. McLinden, "NIST Standard Reference Database 23: Reference Fluid 
Thermodynamic and Transport Properties - REFPROP, Version 9.0, NIST, Standard Reference Data Program," National Institute of Standards and Technology, Gaithersburg, MD, 2010.

[14] F. P. Incropera and D. P. DeWitt, Introduction to Heat Transfer, Fourth ed., New York, NY: Wiley, ISBN: 0471386499, 2001, pp. 412-417.

[15] R. S. Barnes, "A Theory of swellling and gas release for reactor materials," J. of Nucl. Mater., vol. 11, no. 2, pp. 135-148, 1963.

[16] A. T. Churchman, R. S. Barnes and A. H. Cottrell, "Effects of Heat and Pressure on the Swelling of Irradiated Uranium," J.Nucl. Energy, vol. 7, p. 88 96, 1958.

[17] J. B. Rich, G. P. Walters and R. S. Barnes, "The mechanical properties of some highly irradiated Beryllium," J. of Nucl. Mater., vol. 4, no. 3, p. 287-294, 1961. 


\section{APPENDIX A}

Table A. 1 Material properties for U10Mo

\begin{tabular}{|c|c|c|c|c|c|c|c|c|c|c|c|}
\hline \multicolumn{2}{|c|}{ Young's modulus } & \multicolumn{2}{|c|}{ Density } & \multicolumn{2}{|c|}{ Yield Stress } & \multicolumn{2}{|c|}{ Thermal expansion } & \multicolumn{2}{|c|}{ Thermal conductivity } & \multicolumn{2}{|c|}{ Specific heat } \\
\hline$\left[{ }^{\circ} \mathrm{C}\right]$ & {$[\mathrm{GPa}]$} & {$\left[{ }^{\circ} \mathrm{C}\right]$} & {$\left[\mathrm{kg} / \mathrm{m}^{3}\right]$} & {$\left[{ }^{\circ} \mathrm{C}\right]$} & {$[\mathrm{MPa}]$} & {$\left[{ }^{\circ} \mathrm{C}\right]$} & {$\left[10^{-6 /} \mathrm{K}\right]$} & {$\left[{ }^{\circ} \mathrm{C}\right]$} & [W/m.K] & {$\left[{ }^{\circ} \mathrm{C}\right]$} & {$[\mathrm{J} / \mathrm{kgK}]$} \\
\hline 21 & 87.27 & 25 & 17130 & 27 & 937 & 25 & 11.5 & 25 & 12.14 & 0 & 134.81 \\
\hline 200 & 73.54 & 100 & 17060 & 93 & 848 & 100 & 12.2 & 100 & 14.23 & 100 & 141.93 \\
\hline 400 & 51.97 & 200 & 16970 & 204 & 737 & 200 & 13.2 & 200 & 17.16 & 200 & 149.47 \\
\hline \multirow[t]{2}{*}{600} & 33.34 & 300 & 16880 & 316 & 634 & 300 & 14.2 & 300 & 20.09 & 300 & 157.00 \\
\hline & & 400 & 16800 & 427 & 531 & 400 & 15.2 & 400 & 23.02 & 400 & 164.54 \\
\hline \multicolumn{2}{|c|}{ Poisson's Ratio } & 500 & 16710 & 538 & 428 & 500 & 16.2 & 500 & 26.37 & 500 & 171.66 \\
\hline$\left[{ }^{\circ} \mathrm{C}\right]$ & {$[-]$} & 550 & 16660 & 593 & 373 & 600 & 16.6 & 600 & 30.14 & 600 & 179.19 \\
\hline \multirow[t]{2}{*}{25} & 0.324 & 600 & 16620 & & & 700 & 17.9 & 700 & 33.91 & 800 & 193.85 \\
\hline & & 700 & 16530 & & & 900 & 20.5 & 800 & 37.68 & 1000 & 208.92 \\
\hline
\end{tabular}

Table A. 2 Material properties for Zr, Commercially pure, ASTM Grade 702

\begin{tabular}{|c|c|c|c|c|c|c|c|c|c|c|c|}
\hline \multicolumn{2}{|c|}{ Young's modulus } & \multicolumn{2}{|c|}{ Density } & \multicolumn{2}{|c|}{ Yield Stress } & \multicolumn{2}{|c|}{ Thermal expansion } & \multicolumn{2}{|c|}{ Thermal conductivity } & \multicolumn{2}{|c|}{ Specific heat } \\
\hline$\left[{ }^{\circ} \mathrm{C}\right]$ & [GPa] & {$\left[{ }^{\circ} \mathrm{C}\right]$} & {$\left[\mathrm{kg} / \mathrm{m}^{3}\right]$} & {$\left[{ }^{\circ} \mathrm{C}\right]$} & {$[\mathrm{MPa}]$} & {$\left[{ }^{\circ} \mathrm{C}\right]$} & {$\left[10^{-6 /} \mathrm{K}\right]$} & {$\left[{ }^{\circ} \mathrm{C}\right]$} & {$[\mathrm{W} / \mathrm{mK}]$} & {$\left[{ }^{\circ} \mathrm{C}\right]$} & {$[\mathrm{J} / \mathrm{kgK}]$} \\
\hline 21 & 95.89 & 25 & 6499 & 21 & 314.70 & 21.00 & 5.841 & 21.00 & 23.11 & 21.00 & 293.3 \\
\hline 150 & 87.36 & & & 100 & 259.90 & 99.45 & 6.047 & 150.25 & 21.36 & 128.76 & 299.25 \\
\hline 205 & 83.68 & Pois & s Ratio & 149 & 204.00 & 148.05 & 6.178 & 344.55 & 20.58 & 226.37 & 305.16 \\
\hline 292 & 77.74 & {$\left[{ }^{\circ} \mathrm{C}\right]$} & {$[-]$} & 197 & 146.80 & 196.75 & 6.279 & 521.95 & 21.18 & 278.05 & 308.12 \\
\hline 370 & 72.58 & 25 & 0.35 & 259 & 105.10 & 300.15 & 6.532 & 657.05 & 22.61 & 427.33 & 314.16 \\
\hline 426 & 68.71 & & & 297 & 92.62 & 349.85 & 6.653 & 798.85 & 24.02 & 576.61 & 320.19 \\
\hline 516 & 62.76 & & & 348 & 82.50 & 401.15 & 6.754 & 924.85 & 25.40 & 725.89 & 326.23 \\
\hline 611 & 56.40 & & & 400 & 75.95 & 450.15 & 6.876 & 998.85 & 26.16 & 806.28 & 357.67 \\
\hline
\end{tabular}

Table A. 3 Minimum Creep rate for Grade 702 Zirconium alloy

\begin{tabular}{|c|c|c|c|c|c|c|c|c|c|}
\hline \multicolumn{2}{|c|}{$\mathrm{T}=21{ }^{\circ} \mathrm{C}$} & \multicolumn{2}{|c|}{$\mathrm{T}=95^{\circ} \mathrm{C}$} & \multicolumn{2}{|c|}{$\mathrm{T}=205^{\circ} \mathrm{C}$} & \multicolumn{2}{|c|}{$\mathrm{T}=315^{\circ} \mathrm{C}$} & \multicolumn{2}{|c|}{$\mathrm{T}=370^{\circ} \mathrm{C}$} \\
\hline $\begin{array}{c}\text { Strain } \\
{[1 / \mathrm{h}]}\end{array}$ & $\begin{array}{l}\text { Stress } \\
{[\mathrm{MPa}]}\end{array}$ & $\begin{array}{c}\text { Strain } \\
{[1 / \mathrm{h}]}\end{array}$ & $\begin{array}{l}\text { Stress } \\
{[\mathrm{MPa}]}\end{array}$ & $\begin{array}{c}\text { Strain } \\
{[1 / \mathrm{h}]}\end{array}$ & $\begin{array}{l}\text { Stress } \\
{[\mathrm{MPa}]}\end{array}$ & $\begin{array}{c}\text { Strain } \\
{[1 / \mathrm{h}]}\end{array}$ & $\begin{array}{l}\text { Stress } \\
{[\mathrm{MPa}]}\end{array}$ & $\begin{array}{c}\text { Strain } \\
{[1 / \mathrm{h}]}\end{array}$ & $\begin{array}{l}\text { Stress } \\
{[\mathrm{MPa}]}\end{array}$ \\
\hline $2.878 \mathrm{E}-08$ & 119.50 & $2.090 \mathrm{E}-08$ & 88.22 & $1.401 \mathrm{E}-08$ & 54.86 & $2.949 \mathrm{E}-08$ & 52.73 & $3.149 \mathrm{E}-08$ & 42.13 \\
\hline 4.464E-08 & 134.57 & $4.521 \mathrm{E}-08$ & 106.12 & $2.088 \mathrm{E}-08$ & 60.97 & $4.453 \mathrm{E}-08$ & 57.83 & $4.510 \mathrm{E}-08$ & 46.21 \\
\hline $1.018 \mathrm{E}-07$ & 166.20 & $1.018 \mathrm{E}-07$ & 129.34 & $4.457 \mathrm{E}-08$ & 76.30 & $1.016 \mathrm{E}-07$ & 68.66 & $1.015 \mathrm{E}-07$ & 55.59 \\
\hline $2.173 \mathrm{E}-07$ & 205.27 & $2.172 \mathrm{E}-07$ & 155.59 & $1.017 \mathrm{E}-07$ & 94.24 & $2.196 \mathrm{E}-07$ & 80.43 & $2.195 \mathrm{E}-07$ & 65.13 \\
\hline $4.701 \mathrm{E}-07$ & 253.52 & $4.697 \mathrm{E}-07$ & 189.64 & $2.199 \mathrm{E}-07$ & 117.93 & $4.687 \mathrm{E}-07$ & 94.24 & $4.684 \mathrm{E}-07$ & 75.30 \\
\hline $1.003 \mathrm{E}-06$ & 309.01 & $9.891 \mathrm{E}-07$ & 228.12 & $4.693 \mathrm{E}-07$ & 143.75 & $1.000 \mathrm{E}-06$ & 110.40 & $9.996 \mathrm{E}-07$ & 88.22 \\
\hline $1.641 \mathrm{E}-06$ & 352.60 & $2.111 \mathrm{E}-06$ & 270.81 & $9.884 \mathrm{E}-07$ & 177.54 & $2.106 \mathrm{E}-06$ & 129.34 & $2.105 \mathrm{E}-06$ & 102.00 \\
\hline & & $3.642 \mathrm{E}-06$ & 309.01 & $2.110 \mathrm{E}-06$ & 219.27 & $4.495 \mathrm{E}-06$ & 151.54 & & \\
\hline & & & & & & $9.721 \mathrm{E}-06$ & 175.21 & & \\
\hline & & & & & & $2.047 \mathrm{E}-05$ & 205.27 & & \\
\hline
\end{tabular}

Table A. 4 Material properties for Al6061-O

\begin{tabular}{|c|c|c|c|c|c|c|c|c|c|c|c|}
\hline \multicolumn{2}{|c|}{ Young's Modulus } & \multicolumn{2}{|c|}{ Poisson's Ratio } & \multicolumn{2}{|c|}{ Yield Stress } & \multicolumn{2}{|c|}{ Thermal Expansion } & \multicolumn{2}{|c|}{ Conductivity } & \multicolumn{2}{|c|}{ Specific Heat } \\
\hline$\left[{ }^{\circ} \mathrm{C}\right]$ & {$[\mathrm{GPa}]$} & {$\left[{ }^{\circ} \mathrm{C}\right]$} & {$[-]$} & {$\left[{ }^{\circ} \mathrm{C}\right]$} & {$[\mathrm{MPa}]$} & {$\left[{ }^{\circ} \mathrm{C}\right]$} & {$\left[10^{-6} 1 / \mathrm{K}\right]$} & {$\left[{ }^{\circ} \mathrm{C}\right]$} & {$[\mathrm{W} / \mathrm{m}-\mathrm{K}]$} & {$\left[{ }^{\circ} \mathrm{C}\right]$} & {$[\mathrm{J} / \mathrm{kg}-\mathrm{K}]$} \\
\hline 21 & 68.26 & 21 & 0.330 & 21 & 55.16 & 100 & 23.6 & 0 & 177 & 17 & 896 \\
\hline 100 & 65.50 & 100 & 0.334 & 205 & 55.16 & 200 & 24.3 & 77 & 186 & 127 & 942 \\
\hline 150 & 62.74 & 150 & 0.335 & 230 & 44.82 & 300 & 25.4 & 177 & 190 & 227 & 988 \\
\hline 177 & 61.36 & 177 & 0.336 & 260 & 37.92 & \multicolumn{2}{|c|}{ Density } & 277 & 191 & 327 & 1034 \\
\hline 205 & 59.29 & 205 & 0.336 & 315 & 28.96 & {$\left[{ }^{\circ} \mathrm{C}\right]$} & {$\left[\mathrm{kg} / \mathrm{m}^{3}\right]$} & 377 & 188 & 427 & 1080 \\
\hline 230 & 57.23 & 230 & 0.337 & 370 & 20.68 & 21 & 2690 & 477 & 182 & 527 & 1126 \\
\hline 260 & 54.47 & 260 & 0.338 & 425 & 15.17 & 93 & 2690 & 527 & 179 & 582 & 1151 \\
\hline 315 & 46.88 & 315 & 0.360 & 480 & 11.03 & 204 & 2660 & & & & \\
\hline 370 & 37.92 & 370 & 0.400 & 540 & 8.27 & 316 & 2630 & & & & \\
\hline
\end{tabular}




\section{APPENDIX A}

Table A. 5 Thermal creep data for Al6061-O

\begin{tabular}{ccccccc}
\hline Time & Strain & \multicolumn{3}{c}{ STRESS [MPa] } \\
\cline { 3 - 6 }$[\mathrm{h}]$ & {$[\%]$} & $177\left[{ }^{\circ} \mathrm{C}\right]$ & $205\left[{ }^{\circ} \mathrm{C}\right]$ & $260\left[{ }^{\circ} \mathrm{C}\right]$ & $315\left[{ }^{\circ} \mathrm{C}\right]$ & $370\left[{ }^{\circ} \mathrm{C}\right]$ \\
\hline 0.1 & 0.1 & 52.00 & 41.00 & 30.00 & 21.00 & 14.00 \\
0.1 & 0.2 & 55.00 & 45.00 & 31.00 & 22.00 & 15.00 \\
0.1 & 0.5 & 70.00 & 52.00 & 34.00 & 23.00 & 17.00 \\
0.1 & 1.0 & 75.00 & 55.00 & 38.00 & 25.00 & 17.00 \\
\hline 1 & 0.1 & 48.00 & 38.00 & 27.00 & 19.00 & 13.00 \\
1 & 0.2 & 52.00 & 41.00 & 28.00 & 20.00 & 14.00 \\
1 & 0.5 & 62.00 & 45.00 & 30.00 & 21.00 & 15.00 \\
1 & 1.0 & 70.00 & 48.00 & 32.00 & 22.00 & 16.00 \\
\hline 10 & 0.1 & 41.00 & 33.00 & 25.00 & 16.00 & 12.00 \\
10 & 0.2 & 45.00 & 34.00 & 26.00 & 18.00 & 12.00 \\
10 & 0.5 & 55.00 & 38.00 & 28.00 & 19.00 & 13.00 \\
10 & 1.0 & 62.00 & 41.00 & 30.00 & 20.00 & 14.00 \\
\hline 100 & 0.1 & 38.00 & 30.00 & 22.00 & 14.00 & 10.00 \\
100 & 0.2 & 41.00 & 32.00 & 23.00 & 15.00 & 11.00 \\
100 & 0.5 & 52.00 & 34.00 & 26.00 & 17.00 & 12.00 \\
100 & 1.0 & 59.00 & 38.00 & 27.00 & 18.00 & 12.00 \\
\hline 1000 & 0.1 & 38.00 & 28.00 & 20.00 & 12.00 & 9.00 \\
1000 & 0.2 & 41.00 & 30.00 & 21.00 & 13.00 & 10.00 \\
1000 & 0.5 & 48.00 & 31.00 & 23.00 & 14.00 & 10.00 \\
1000 & 1.0 & 55.00 & 32.00 & 23.00 & 15.00 & 11.00 \\
\hline
\end{tabular}

Table A. 6 Yield Stress of AL6061-O with respect to fluence

\begin{tabular}{ccccc}
\hline \multicolumn{2}{c}{$50^{\circ} \mathrm{C}$} & & \multicolumn{2}{c}{$150{ }^{\circ} \mathrm{C}$} \\
\cline { 1 - 2 } \cline { 5 - 5 } $\begin{array}{c}\text { Fluence } \\
{\left[\mathrm{n} / \mathrm{m}^{2}\right]}\end{array}$ & $\begin{array}{c}\text { Yield Stress } \\
{[\mathrm{MPa}]}\end{array}$ & & $\begin{array}{c}\text { Fluence } \\
{\left[\mathrm{n} / \mathrm{m}^{2}\right]}\end{array}$ & $\begin{array}{c}\text { Yield Stress } \\
{[\mathrm{MPa}]}\end{array}$ \\
\cline { 1 - 2 } \cline { 5 - 6 } $1.00 \mathrm{E}+25$ & 129.10 & & $1.00 \mathrm{E}+25$ & 96.03 \\
$4.60 \mathrm{E}+25$ & 162.77 & & $4.60 \mathrm{E}+25$ & 127.55 \\
$1.00 \mathrm{E}+26$ & 213.34 & & $1.00 \mathrm{E}+26$ & 174.82 \\
$9.60 \mathrm{E}+26$ & 292.26 & & $1.00 \mathrm{E}+27$ & 250.18 \\
$1.00 \mathrm{E}+27$ & 295.93 & & & \\
\hline
\end{tabular}

Table A. 7 Swelling of Al6061

\begin{tabular}{cc}
\hline \multicolumn{2}{c}{ Swelling due to Fluence } \\
\hline $\begin{array}{c}\text { Fluence } \\
{\left[\mathrm{n} / \mathrm{m}^{2}\right]}\end{array}$ & $\begin{array}{c}\text { Swelling } \\
{[\%]}\end{array}$ \\
\hline $1.82 \mathrm{E}+25$ & 0.01000 \\
$2.88 \mathrm{E}+26$ & 0.16746 \\
$1.83 \mathrm{E}+27$ & 2.02070 \\
\hline
\end{tabular}

